\title{
Bonus Payments and Fund Managers' Behavior: Trans-Atlantic Evidence
}

\author{
Thomas P. Gehrig, University of Freiburg, Germany, and CEPR, London \\ Torben Lütje, Deutsche Asset Management and Leibniz Universitaet Hannover \\ Lukas Menkhoff, Leibniz Universitaet Hannover, Germany
}

\author{
Discussion Paper No.411 \\ December 2008 \\ ISSN 0949-9962
}

\begin{abstract}
This questionnaire survey of fund managers in the United States, Germany and Switzerland documents a distinctly positive influence of bonus payments on investment behavior on both sides of the Atlantic. Higher bonus payments are significantly related to higher working effort but not to risk taking. They also seem to induce fund managers to rely more on fundamental information. Findings within regions are confirmed by Trans-Atlantic evidence as US fund managers receive larger bonuses but also show the effects to a higher degree. The effects documented are stronger for relative than for absolute performance assessment.
\end{abstract}

JEL-Classification:

Keywords:
G23, G14

Fund managers, incentives, fundamental information

We would like to thank participants at the European Economic Association conference in Amsterdam, at seminars in Cologne and Frankfurt, Gerhard Illing, Alexander Kempf, Armin Schmutzler and in particular Michael Melvin and two anonymous referees for very helpful comments. We very much appreciate the contributions made by the fund managers who were generously available for interviews and took time to respond to the survey. We gratefully acknowledge a supporting letter by the German Investment and Asset Management Association 'BVI' and financial support by the Volkswagen Foundation.

Thomas P. Gehrig, Department of Economics, University of Freiburg, Platz der Alten Synagoge, 79085 Freiburg, Germany, thomas.gehrig@vwl.uni-freiburg.de;

Torben Lütje, Lukas Menkhoff, Department of Economics, Leibniz Universitaet Hannover, Koenigsworther Platz 1, 30167 Hannover, Germany, menkhoff@gif.uni-hannover.de, torben.luetje@db.com 


\section{Bonus Payments and Fund Managers' Behavior: Trans-Atlantic Evidence}

\section{Introduction}

With the dramatic growth of the asset management industry in global capital markets the role of fund managers increasingly attracts public interest. Especially in periods of crises it has become popular to blame fund managers for not having reacted in time, or even for triggering crises and generating volatility in the first place. This critical assessment is compounded by the industry practice to reward fund managers by bonus payments. Bonus payments are sometimes regarded as an invitation to gambling. In case the gamble is successful the fund manager earns high payments, while the financial risk of bad outcomes remains largely with the investors. ${ }^{1}$ We know from theoretical and empirical studies that these concerns are justified (see Stracca, 2006) but we also know that incentives may have welcome effects on behavior and fund performance (e.g. Dass et al., 2008). Thus, there is a clear motivation to learn more about how fund managers react to bonus payments.

Due to intrinsic data limitations empirical knowledge about the link between bonus payments and investment behavior at the individual level is rather limited. Both investment strategies and managers' individual payment contracts are highly confidential information. Hence, it is difficult for outside researchers to directly observe the incentive effects of bonus payments. In fact, Chevalier and Ellison $(1997,1999)$ provide a rare analysis by linking personal information to individual performance data for U.S. fund managers. ${ }^{2}$ In the absence of direct information about contractual details, demographic data, managers' views and performance, questionnaires provide a useful option to learn indirectly about real behavior.

\footnotetext{
${ }^{1}$ Accordingly, there is a debate on optimal incentive contracts (in fund management) which we selectively discuss in Section 2.

${ }^{2}$ Their focus is on career concerns within organizations as an incentive device. They cannot analyze determinants of bonus payments across firms.
} 
In order to exploit industry specific expertise we conduct an international questionnaire survey. This survey relies on responses of professionals active in three different countries with quite different equity cultures and pension systems, namely the United States, Germany and Switzerland. ${ }^{3}$ Our approach allows us to solicit comparative information about the effects of bonus payments on individuals' conduct without requiring the respondents to provide confidential information such as the personal contract details.

In our data set we find that bonus payments - relative to base salary - are significantly higher in the United States than in Continental Europe, i.e. Germany and Switzerland. Moreover, bonus payments increase with seniority, in the U.S. even more than in Continental Europe, and bigger companies rely more heavily on bonuses. All this information is consistent with available evidence.

Based on this data we test three possible effects of bonus payments, separated for the U.S. and Continental Europe: first, we find that bonuses tend to stimulate effort. Second, there is little evidence of bonus-induced risk taking. Third, we find that bonus payments tend to make managers more sensitive to fundamental information. Overall, incentives seem to work well within regions.

This positive view on bonus payments is confirmed by an analysis across the Atlantic: U.S. fund managers receive about 5-times higher bonuses and work more, take higher risks (within a-priori agreed limits) and seem to care more about fundamentals. Finally, the favorable effect of incentives seems to be stronger when bonus payments depend on relative vs. absolute fund performance assessment.

Our study contributes in two directions to the literature. First, we complement available empirical evidence on the impact of incentives, such as the work by Chevalier and Ellison

\footnotetext{
${ }^{3}$ Despite these differences, the German and US market seem to be quite competitive, if we interpret the fund managers' difficulty to beat the market in this way (see Otten and Bams, 2002).
} 
(1997, 1999), Massa and Patgiri (2007, 2007a) and Dass et al. (2008) on U.S. fund managers, by a different kind of evidence. Survey evidence exploits the fund managers' perspective on effort, risk taking and use of information and also covers a large set of control variables. Second, we extend available academic survey studies on fund managers' compensation which focus either on the U.S. or on European countries by a Trans-Atlantic study.

The paper is organized as follows: Section 2 discusses the importance of explicit and implicit incentives in fund management. Section 3 describes data. Section 4 compares transAtlantic bonus payment schemes. After consideration of institutional correlates of high bonus payment in Section 5, its interdependence with working effort is analyzed in Section 6. Then, the correlation between bonus and risk-taking as well as fundamental investment orientation will be discussed in Section 7 and 8, respectively. Section 9 analyzes the effect from relative vs. absolute performance assessment and Section 10 concludes the paper.

\section{Incentives in the fund management industry}

There is a broad literature on the role of performance based contracts for portfolio performance. ${ }^{4}$ This literature is largely of a theoretical nature and emphasizes the role of incentives, both explicit and implicit, for the provision of effort, the control of risk and the acquisition of information.

Explicit incentives are typically incorporated into remuneration packages. They include performance related bonuses, where performance is measured either directly as an absolute statistic or relative to some benchmark in order to reward relative success. ${ }^{5}$ Implicit incentives are typically provided dynamically by career opportunities. Good (relative) performance may

\footnotetext{
${ }^{4}$ See e.g. Bhattacharya and Pfleiderer (1985), Grinblatt and Titman (1989), Zwiebel (1995), Prendergast and Stole (1996), Admati and Pfleiderer (1997), Arora and Ou-Yang (2001), Bhattacharya (2001), Ou-Yang (2003) and the recent survey by Stracca (2006).

${ }^{5}$ The seminal contribution on relative performance evaluation is Holmström (1999); the working paper appeared already in 1979.
} 
be rewarded with career steps, both internally within a company or externally through the market from competitors (Fama, 1980).

While the relation between incentives and performance has been documented in many industries (see Gibbons and Murphy, 1990) very little is known in the case of the fund management industry. To the best of our knowledge there is no publicly available evidence for the international fund management industry so far. This shortcoming is particularly serious, since the work of Admati and Pfleiderer (1997) suggests that the relative performance effects of static contracts on individual behavior of fund managers may in market equilibrium be completely counteracted by the optimal parameter choice of the incentive schemes. ${ }^{6}$ Moreover, performance evaluation may have impact on the evaluation of assets in equilibrium (Gümbel, 2005, Kapur and Timmermann, 2005, Dasgupta and Prat, 2006).

Hence, in this industry career concerns probably provide strong relative incentives. Those tend to align managers' interest with investors' interest especially at an early stage in the career. However, as managers advance in the organization these implicit incentives decrease with age and experience. Accordingly, Gibbons and Murphy (1992) argue that in an optimal financial arrangement explicit performance-related incentives should substitute for implicit (career) incentives increasingly as fund managers advance in their career. In other words, explicit bonus payments should increase with the manager's position within the organization.

Since neither individual base salaries nor bonus payments are usually publicized, it is not surprising to see that mainly career concerns within an organization have been scrutinized so far. Chevalier and Ellison (1997) discover some indirect evidence of risk taking behavior. In particular, they find that US fund managers seem to adjust their portfolios towards the end

\footnotetext{
${ }^{6}$ This problem does not arise under absolute compensation schemes since those are not affected by market statistics, and, hence, behavior of others.
} 
of the calendar year. Chevalier and Ellison (1999) analyze the determinants of termination of fund managers and find that low performance is important. Such a policy provides an incentive to engage in risky investments after a period of low performance - a strategy known as "gambling for resurrection" - in order to avoid being fired. Moreover, younger age seems to lead to investment behavior that is oriented towards the benchmark with respect to mean risk levels and asset allocation.

More recent work has also examined explicit incentives. Carpenter (2000) models that risk averse fund managers react on an increase of the incentive fee level by a reduction of the fund's risk. In a different framework, such as a different utility function, Kouwenberg and Ziemba (2007) derive that fund managers use riskier strategies with higher incentive fees. The latter view is supported by evidence from US mutual funds (Massa and Patgiri, 2007) and from the hedge fund industry (e.g. Kouwenberg and Ziemba, 2007). As another aspect, Basak et al. (2007) find that benchmarking contributes to limiting extreme risk taking which results from the fund managers' incentive to stimulate fund inflows by high returns.

While, in principle, the riskiness of a portfolio can be observed ex-post it is more difficult to evaluate the acquisition and proper use of private information ex ante. For example, there are situations where relying on public information and even herding may be a rational low cost way of acquiring information which could affect fund managers' behavior. By following the observed behavior of other managers they might free-ride from the information of others and could, thus, rationally try to avoid costly acquisition - possibly even duplication of private information (Lakonishok et al., 1992, Grinblatt et al., 1995). Fund managers might have strong incentives to herd, if their incentives schemes punish them harshly for relatively bad performance while smaller deviations are sanctioned minimally. While herding may be a 
low cost information strategy it imposes considerable risks on investors. ${ }^{7}$ This risk can be reduced as fund managers increasingly rely on fundamentals. In this respect, Dass et al. (2008) find that high incentives induce managers to follow strategies different from the herd.

In order to assess the incentive effects on investment behavior of real world fund managers we develop a questionnaire to elicit information about explicit incentives such as bonus payments rewarding absolute and relative performance, which we complement by information about implicit incentives, proxied by age, position and experience. Moreover, we collect information about our target variables, i.e. working effort, risk attitude and fundamental orientation, and various control variables, such as size of the asset management firm, the manager's specialization on asset type and fund specialization.

\section{Data}

This study is based on a questionnaire survey being conducted with fund managers in the United States, Germany and Switzerland in 2003/04. In this section we present information about the questionnaire design, pretests and the process of data collection. ${ }^{8}$

\subsection{Questionnaire design and pretests}

The questionnaire was designed to provide personal information about respondents' characteristics such as position, education, age and risk attitudes, about respondents' views on the management industry, and about their personal investment strategies. In order to provide incentives to respond we developed a rather short questionnaire and avoided to ask moderately confidential information. For details see the questionnaire in Appendix 1.

\footnotetext{
${ }^{7}$ The risk of following a strategy which relies on easily available information, such as following a herding strategy, may be increased by strategic forecasting which creates incentives for misreporting of available private information (Ottaviani and Sørensen, 2006).

${ }^{8}$ There are many important questionnaire based studies in financial economics, such as Bodnar et al. (1996), Welch (2000), Graham and Harvey (2001) or Brav et al. (2005).
} 
Since the quality and significance of the answers does not only depend on a suitable selection of questions, but also on their correct formulation, we discussed draft versions of the questionnaire with professional asset managers in numerous personal interviews in each country in order to avoid misinterpretations. Pretests in each country finally confirmed the questionnaire's applicability. During the period of April to August 2003 the fund management companies in Germany and Switzerland were contacted. Thereafter, from September 2003 to February 2004, we collected questionnaires from fund managers in the United States. ${ }^{9}$

\subsection{Participation rate and responses}

In total, we received 325 questionnaire responses from professional fund managers that are useful for the analysis of bonus payments. It comprises 121 questionnaires from the United States, 173 from Germany and 31 from Switzerland.

We sent our questionnaires to all major firms in the three countries. In the US we addressed the top 250 firms ranked by worldwide assets under management and we received response from fund managers of 68 different firms (participation rate of US firms: 27.2\%). In Germany we sent questionnaires to 66 member firms of the BVI with major investment segments in equities and bonds, respectively, and fund managers of 50 different companies participated in the survey (participation rate of German firms: 75.8\%). The high participation rate of German companies is also attributable to the letter of recommendation by the German investment and asset management association 'BVI'. In Switzerland 18 of active 62 member firms of the 'Swiss Funds Association' with major investment segments in equities and bonds, respectively participated (participation rate of Swiss firms: 29.0\%). In total, this yields the

\footnotetext{
${ }^{9}$ According to the best of our knowledge, this is the first international survey of this kind. Beckmann et al. (2008) and Beckmann and Menkhoff (2008) also rely on some of our data although with a different focus. Earlier work on the US includes Shiller and Pound (1989) or Farnsworth and Taylor (2006), work on Germany includes Arnswald (2001), Menkhoff et al. (2006) or Drachter et al. (2007).
} 
high participation rate of $36.0 \%$ of investment companies. ${ }^{10}$ Unfortunately, we cannot report an exact response rate regarding the number of sent out questionnaires because we addressed the head of fund management and usually attached between two to six questionnaires - depending on firm size - which were forwarded to the single fund managers who returned the filled questionnaires directly to us. Strategic answers are not expected due to guaranteed anonymity of participants.

The representativeness of the collected data sample in each country is confirmed by $\underline{\mathrm{Ta}}-$ ble 1: the null hypothesis of no difference between the size of responding asset management firms and the size of firms in the respective market cannot be rejected. Moreover, larger investment firms typically employ more asset managers, a fact being reflected in the data set (see Table 1). Finally, the demographic characteristics of fund managers in our sample are almost identical to those in different survey studies for the US (Farnsworth and Taylor, 2006) and Germany (Arnswald, 2001, Menkhoff et al., 2006), indicating that our data are not distorted by a selection bias. ${ }^{11}$ Table 2 presents the typical personal characteristics of the surveyed asset managers clustered by country.

\section{Description of fund managers' bonus payments in three countries}

The bonus payment is the dominant explicit incentive of fund managers. Bonuses are typically paid once a year in addition to the fixed salary. The size of the bonus is measured in percentage of the fixed salary. ${ }^{12}$ According to our sample, the median bonus for US fund managers is $100 \%$, while the mean is even higher at $184 \%$ (see Table 3). The respective figures for

\footnotetext{
${ }^{10}$ This seems to be a reasonable result compared to the response rates of similarly designed surveys, such as Shiller and Pound (1989) or Graham and Harvey (2001) with 45\% and 9\%, respectively.

${ }^{11}$ Strictly speaking, our data is similar to other survey data sets. Among these other surveys Arnswald's study comes close to a complete coverage of stock fund managers in Germany (due to the involvement of the Deutsche Bundesbank) - this indicates that our data is even representative for this market segment.

${ }^{12}$ We have not asked for the level of salary in order to avoid less and selective responses.
} 
the European markets are considerably lower: the median bonus in Germany is $25 \%$ and the mean is $30 \%$. The Swiss figures are $30 \%$ and $37 \%$, respectively. Moreover, Table 3 shows that bonus size generally increases with the fund managers' position as predicted by Gibbons and Murphy (1992)(more details in Appendix 2, Figure 1).

Hence, we establish that the US industry has a much higher level of bonus payments as well as a somewhat stronger relative increase, indicating that these explicit incentives for US fund managers are stronger than for their Continental European counterparts. ${ }^{13} \mathrm{~A}$ formal examination testing for significant differences in bonus payments shows, indeed, that the US is very different from Continental Europe whereas Germany and Switzerland are not significantly different from each other (Table 4). So, in the following we will just compare the US with Continental Europe, in short: CE, comprising of Germany and Switzerland.

\section{Institutional correlates of high bonus payments}

Since position apparently affects bonus payments it is natural to ask about the existence of further determinants of bonus payments. For example, it may seem plausible that age and experience, which again are correlated with position, exert an independent influence on bonus size. It seems thus advisable to run a multivariate regression. Because bonus payments are left-censored data, a Tobit approach is chosen in this case.

We put all available institutional items into this regression and find that only very few of them are important (see Table 5, also listing the non-significant variables). There are just two statistically significant determinants of bonus size for the US and Continental Europe (CE) as well, i.e. position and firm size ("working for bigger companies" measured by assets under management). So, the intuitively appealing position-argument holds in a multivariate context 
too and appears to be stronger than possible influences from age, experience or other variables. The second "world-wide" determinant, firm size, means that bigger companies pay higher bonuses (see also Farnsworth and Taylor, 2006, for the US). This may indicate that larger firms rely more on bonus payments as an incentive mechanism. An explanation could be that larger fund management firms must rely stronger on explicit incentive schemes as implicit incentives may be weaker.

In addition to these "world-wide" determinants, there is a specific determinant for CE: we find that female managers earn higher bonuses than male managers. However, evidence is only marginally significant and also not robust to the exact specification.

In another question we have directly asked fund managers about criteria that determine their bonus size. Interviews have shaped four important categories of determinants which are given in Table 6 . These possible determinants are analyzed in three ways: columns (1) and (2) present the share of respondents that give highest relevance to these determinants, separately for the US and CE. Relative fund performance is the most important determinant in the US as almost half of all respondents give it the highest relevance, whereas other determinants receive about a quarter at most. Thereafter, business development ranks before subjective assessment whereas absolute fund performance does not seem to be important. The situation is different in CE: here business development is somewhat more important than relative fund performance. Rank positions three and four are the same as in the US. Column (3) in Table 6 shows that the difference between the US and CE is indeed statistically significant for business development and relative fund performance.

In a next step we correlate these determinants of bonus with the size of bonus (see columns 4 and 5). We find that coefficients are mostly positive, indicating that higher bonuses

\footnotetext{
${ }^{13}$ Drachter et al. (2007) present evidence consistent with our survey data in that the median fund manager in the US earns about 70\% more than in Germany and the gap widens to a multiple of about three
} 
lend importance to determinants from the viewpoint of fund managers. For the US, the correlation is significant for business development only. This relation is strongly driven by fund mangers in higher positions who receive higher bonuses and where bonus depends on company success. ${ }^{14}$ The influence of fund performance is comparatively weaker, however (see also Farnsworth and Taylor, 2006). This may reveal a truly widespread and self-evident importance of relative fund performance, just as shown by its high overall importance (see column 1). It is interesting to see, that the CE experience is different: here we observe a kind of trade-off between increasing importance of relative fund performance and decreasing importance of subjective assessment. This may be caused by the earlier observed fact that larger firms, who rely more on explicit incentives, prefer rather objective indicators - such as fund performance - as incentives than subjective assessments. ${ }^{15}$ It is a side-effect of these relations that high bonus payments in $\mathrm{CE}$ are correlated with an important relative fund performance. In this sense, any impact from bonuses can be also understood as an investment behavior that strongly considers relative fund performance (see more in Section 9).

Summing up, the size of bonus payments has two "world-wide" institutional determinants, i.e. position and company size. Whereas the US and CE are not very different in this respect, fund managers in both regions see somewhat different decisive criteria for bonus size. Relative fund performance is important everywhere (although with a p-value of 0.103 only for the US). However, only US fund managers with high bonuses mention business development of the company, a finding influenced by managers in higher positions.

for the top $10 \%$ percentile.

${ }^{14}$ When controlling for the manager's position, the partial correlation between bonus payment and business development is not significant anymore with a coefficient of 0.145 (p-value 0.131 ).

${ }^{15}$ Here, the control for company size indeed weakens the correlation between bonus payment and subjective assessment with a coefficient of $-0.123 *$ (p-value 0.097 ). 


\section{Bonus and working effort}

Having seen that bonus size depends to some degree on institutional determinants, we now turn to the individual level: according to elementary theory and empirical studies, bonus payments should go along with higher working effort (e.g. Lazear, 2000). ${ }^{16}$ We confirm this pattern for our survey data, too, lending credence to the data quality.

The measure of working effort which we apply is the "average working hours per week", an information which respondents provide about themselves. The median category for the US is 51 to 55 hours, for CE it is 46 to 50 hours and this difference is statistically significant. The longer working hours in the US may have a cultural root as they are observed in other occupations as well. The difference becomes somewhat smaller but stays highly significant when we control for position (not presented). Moreover, working effort is in the US and CE strongly positively correlated with bonus size (see top at Table 7, see also Appendix 2, Figure 2).

The problem is, however, that any such bivariate relation is influenced by other factors as discussed in Section 2. We thus run a multivariate regression, covering a set of control variables. These are the systematic determinants of bonus size found in Section 5, i.e. higher position and working for a bigger company. Additional control variables are incentives possibly competing with the impact from bonus payments, i.e. age and experience. The result in Table 7 shows that indeed higher bonus payments are significantly related to more working effort, although only weakly significant for the US. We find, moreover, that bigger firms in the US may provide an environment or enforce a style where working hours are longer. Interestingly, fund managers in high positions and younger fund managers in the US tend to work

\footnotetext{
${ }^{16}$ In a strict sense working effort may be higher in anticipation of bonus payment (although bonus does not directly depend on effort but on performance). Moreover, bonus payments may stimulate intrinsic motivation and thus working effort.
} 
harder (see also Gibbons and Murphy, 1992, Holmström, 1999) but coefficients are not significant in the multivariate approach.

The consideration of further possible determinants of working effort reveals new insights which may - due to some collinearity between the various determinants - weaken the influence of the bonus variable. So, in the US, research and data procurement, i.e. basically another proxy of effort, are highly positively correlated. Also lower education seems to provide an incentive to work harder, possibly to compensate the educational disadvantage. In $\mathrm{CE}$, it is only the variable managing bigger funds, i.e. a proxy for firm size, which becomes significant. This obviously mirrors the variable working for bigger companies that is important in the US.

In summary, the classic economic intuition is supported by our survey data: the bonus payment is significantly related to more working effort. Perhaps surprisingly, other incentives, such as age, are of relatively minor importance to understand the degree of working effort.

\section{$7 \quad$ Bonus and risk-taking}

Having learned that plausible ex ante expectations on bonus and working effort are supported by the data, what about the other classical relation, i.e. on bonus and risk-taking (see Section 2)? We do not find evidence that bonus would increase risk-taking.

In order to capture risk-taking of fund managers we use the so-called "tracking error", i.e. the deviation of a portfolio return from a benchmark, such as a market index. As the measures of willingness to take risk, we ask for the tracking error that the fund manager is allowed to practice (in a subjective categorization between high tracking error and indexing) and then the tracking error the same manager does actually practice. The difference between both answers provides information about the degree that the fund manager is willing to actively use 
the maximum tracking error allowed and thus provides a measure of realized risk-taking. We call this measure the "degree of active management".

Next, we analyze the distributions of the tracking error allowed and practiced. Fund managers perceive their allowed tracking error to be clearly different from indexing. More than $98 \%$ do not answer the question "what trading style are you allowed" with response category 6, i.e. indexing. Whereas there emerges no significant difference between the US and CE in this respect, the degree of active management - i.e. the difference between tracking error allowed and practiced - is remarkably different (see Appendix 2, Figure 3): US fund managers prefer with $81.8 \%$ to use the maximum tracking error allowed, $\mathrm{CE}$ fund managers do so to $53.1 \%$ only, and more than $40 \%$ of the latter do not fully use the tracking error allowed. It is interesting to note the relation with bonus and the tracking error allowed within countries: higher bonus is related with higher tracking error allowed, indicating that active fund management has higher incentives. ${ }^{17}$ Regarding the degree of active management, however, bonus is not related within countries (see top at Table 8). It seems plausible although that the higher US bonus level could be responsible for the observed higher degree of active management in the US, indicating more risk-taking.

When we come to explaining the degree of risk-taking, we confirm the finding of the bivariate analysis: bonus does not seem to be important within countries. ${ }^{18}$ Table 8 shows, however, that experienced fund managers take more risks in CE. Including the research and data procurement variable in the regression for $\mathrm{CE}$ indicates that careful analysis may be seen as a good precondition for more risk-taking. In addition to this effect, experience becomes

\footnotetext{
${ }^{17}$ Coefficients of the Spearman rank correlation between lower tracking error allowed and higher bonus are $-0.159 *$ ( $p$-value 0.081 ) for the US and -0.186 (p-value 0.009 ) for CE.

${ }^{18}$ Bonus may nevertheless be important if our measure is distorted. A referee notes in this respect that we do not exactly measure the "slope of the incentive scheme" and that we do not control for possible caps of the bonus. Moreover, Kempf et al. (2007) show that also employment risk influences an impact from compensation on risk taking.
} 
more significant. Moreover, younger fund managers more fully use allowed risk-taking. ${ }^{19}$ For the US, by contrast, fund managers stick so closely to their tracking error allowed that there emerge no significant influences except a slight effect that mutual fund managers are somewhat more aggressive than those managing special funds.

In summary, there is a surprise in findings as the bonus size is not related to the degree of risk-taking within countries. ${ }^{20}$ It may be that the overall higher bonus level of the US firms encourages their fund managers to almost fully use the maximum tracking error allowed. Interestingly, implicit incentives caused by experience and age are possibly more important to understand risk-taking.

\section{Bonus and fundamental investment orientation}

Bonus payments are not only related to working effort and risk-taking but could also influence the degree to which fundamental facts influence investment decisions. Our data support unanimously that higher bonus size is related with stronger fundamental orientation. Fundamental orientation itself contradicts a strong reliance on other fund managers' behavior, i.e. herding (see the discussion of herding in Section 2).

In order to measure the degree of fundamental orientation we have simply asked fund managers to assess the relevance of "fundamental facts about the company / market" as a source of information used in making investment decisions. It is reassuring that fundamentals are assessed by an above average degree of relevance by virtually all fund managers; US fund managers give significantly higher importance to fundamental facts than their CE colleagues (see Appendix 2, Figure 4).

\footnotetext{
${ }^{19}$ This relation seems to be different from the Chevalier and Ellison (1999) finding that younger fund managers are less risk averse in the sense of closer adherence to the benchmark. However, our measure of risk is somewhat different and we control age for experience. These differences might be also important for related analyses that state an influence from age on risk taking as it has been established for investment newsletters (Graham, 1999) and for financial analysts (Li, 2002).
} 
When we analyze the relation of fundamental orientation with bonus payments, there emerge positive correlations for both groups, US as well as CE fund managers (see top at $\underline{\text { Ta- }}$ ble 9). When we control this relation for the other variables introduced above, higher bonus is still a significant determinant of fundamental orientation (see the middle part in Table 9). In the US, fund managers in lower positions are even more fundamentally oriented, in CE this applies to fund managers from bigger companies. ${ }^{21}$ Finally, when we consider further possible determinants, it is no surprise that more research and data procurement is very highly positively correlated with reliance on fundamentals: thus, this variable is clearly significant in the US as well as in CE (see bottom at Table 9). In the European context, research and data procurement in combination with the variable to manage rather equities than bonds explains better the degree of fundamentalism and makes the bonus variable insignificant.

In summary, our study suggests that higher bonus payments provide an incentive to beat the market by means of fundamental orientation and thus indirectly limit the incentive towards herding (Lakonishok et al., 1992, Massa and Patgiri, 2007a).

\section{Relative versus absolute performance assessment}

As a last aspect we deepen the analysis of bonus payments by focusing on the role of relative performance as determinant of the bonus. Evidence shows that the effect of bonus payments is tentatively stronger when relative and less so absolute fund performance is taken as basis for the assessment.

The academic literature on the consequences of relative performance measurement is often quite skeptical. Admati and Pfleiderer (1997, p.324) "find that commonly used bench-

\footnotetext{
${ }^{20}$ This result is consistent with Carpenter (2000) though.

${ }^{21}$ As one referee notes, "perhaps firms with higher bonus payments are also more , serious' and more serious firms enforce stricter fundamental orientation". Then it would be less certain whether bonus payments have an impact on fundamental orientation independent from firms' size (in CE).
} 
mark-adjusted compensation schemes ... tend to weaken a manager's incentives to expend effort (or are at best irrelevant in this context)". Bhattacharya and Pfleiderer (1985) conjecture - based on purely theoretical considerations - that relative incentive schemes are counteracted by endogenous behavior. Hence, one does not expect that relative bonuses are a strong stimulus to working effort in our sample. ${ }^{22}$ Eichberger et al. (1999) show that relative performance contracts in the market may lead to inefficient outcomes as fund managers do not invest enough effort in getting (fundamental) information (see also Gümbel, 2005). Palomino and Prat (2003) derive that an optimal bonus contract should link the payment to the realization of a desired threshold portfolio return, whereas otherwise managers may follow too risky investment policies. Thus, theoretical studies derive unfavorable predictions about the impact of relative performance assessment on working effort, risk taking and the use of fundamental information, although Basak et al. (2007) derive a positive effect by limiting extreme risk taking. We test whether fund managers' attitudes towards the three above mentioned dimensions of their behavior are related to the importance of relative performance assessment for the size of their individual bonus.

The empirical approach is straight forward as we define a new variable "relative performance" which measures the difference between the importance of "relative fund performance" and "absolute fund performance" (these variables are described in Table 6). This new variable is then added to the former regressions as they are documented in Tables 7 to 9. As results do not change much we only document the coefficients of the variables of interest, i.e. the effect of a "higher bonus" and of a higher importance of "relative performance". Table 10 shows the same pattern as the more detailed Tables 7 to 9 gave before: Bonus and relative performance are positively related to a higher working effort and a stronger fundamental ori-

\footnotetext{
22 Jenter and Kanaan (2006) show empirically that CEO turnover is only partially affected by relative performance of a firm but also heavily by the absolute performance of industries and the market. This
} 
entation but not to a more active management style. ${ }^{23}$ The effect from relative performance measurement is in the US stronger on working effort and in CE stronger on fundamental orientation. Results for CE are often only borderline significant with p-values between 0.10 and 0.13 but the message seems clear: relative performance assessment has an additional impact in the same direction as the size of the bonus. It may be reassuring that high incentives have been found to strengthen a more fundamental approach in a different empirical setting too (Dass et al., 2008, Massa and Patgiri, 2007).

\section{Conclusions}

This paper analyzes how bonus payments shape behavior of fund managers. To learn more about bonuses, we conducted a survey study in major markets, i.e. the US as well as Germany and Switzerland. The US is regarded as a more market-based financial system, whereas Continental Europe's financial system is more bank-based. To some surprise, we find little evidence of different investment cultures across the Atlantic. While the order of magnitude of bonus payments clearly varies strongly between the US and Continental Europe, the marginal effects on effort, risk taking and information usage do not differ widely.

Indeed we find that bonus payments are significantly higher in the US than in Continental Europe relative to base salary. Also the increase over the career is steeper in the US. Moreover, we identify institutional determinants of bonus size, i.e. the position reached and company size.

As the core of our study, we can document that bonus size seems to have desirable effects on effort, risk taking and fundamental orientation. First, bonus size is clearly positively

may also contribute to weaken the impact of relative performance assessment.

${ }^{23}$ These results hold qualitatively when we allow further variables to enter the regressions as we did before, see Tables 7 to 9 at the bottom each. Results are also robust to an alternative approach of measuring relative performance assessment by way of an interaction variable with bonus size. 
related to the working effort of fund managers, whereas age and experience are not. Second, we find that the relation between bonus size and willingness to take risk is insignificant within regions. However, the US fund managers - who receive 5-times higher bonuses - practice a more active management than their CE colleagues. If there are incentives that determine risktaking they seem to be related rather to experience and age but less so to bonus payments. Third, it is analyzed whether the incentives given by bonus payments discipline the fund managers' behavior to rely more on fundamental facts in investment decisions. Our evidence favors this hypothesis.

Interestingly, our three findings are consistent with the Trans-Atlantic comparison, as US fund managers receive higher bonuses and bonuses depend more on relative performance assessment but they also work longer, are willing to take higher risks and behave more in line with fundamentals. Finally, we find that the positive effects from bonus size on working effort and fundamental orientation are strengthened by relative vs. absolute performance assessment. In summary, our evidence supports the notion that bonus payments shape behavior in a useful way.

\section{References}

Admati, Anat R. and Paul Pfleiderer (1997), Does It All Add Up? Benchmarks and the Compensation of Active Portfolio Managers, Journal of Business, 70:3, 323-350.

Arnswald, Torsten (2001), Investment Behaviour of German Equity Fund Managers, An Exploratory Analysis of Survey Data, Deutsche Bundesbank Discussion Paper 08/01, Frankfurt.

Arora, Navneet and Hui Ou-Yang (2001), Explicit and Implicit Incentives in a Delegated Portfolio Management Problem: Theory and Evidence, Working Paper.

Basak, Suleyman, Anna Pavlova and Alex Shapiro (2007), Offsetting the Incentives: Risk Shifting and Benefits of Benchmarking in Money Management, Journal of Banking and Finance, forthcoming.

Beckmann, Daniela and Lukas Menkhoff (2008), Will Women Be Women? Analyzing the Gender Difference among Financial Experts, Kyklos, 61:3, 364-384. 
Beckmann, Daniela, Lukas Menkhoff and Megumi Suto (2008), Does Culture Influence Asset Managers' Views and Behavior?, Journal of Economic Behavior and Organization, 67:3/4, 624-643.

Bhattacharya, Sudipto (2001), Incentives in Funds Management: Theories and Some Facts, Working Paper, London School of Economics and Political Science.

Bhattacharya, Sudipto and Paul Pfleiderer (1985), Delegated Portfolio Management, Journal of Economic Theory, 36, 1-25.

Bodnar, Gordon M., Gregory S. Hayt and Richard C. Marston (1998), Wharton Survey of Financial Risk Management by US Non-Financial Firms, Financial Management, 27:4, 70-91.

Brav, Alon, John R. Graham, Campbell R. Harvey and Roni Michaely (2005), Payout Policy in the $21^{\text {st }}$ Century, Journal of Financial Economics, 77, 483-527.

Carpenter, Jennifer N. (2000), Does Option Compensation Increase Managerial Risk Appetite?, Journal of Finance, 55:5, 2311-2331.

Chevalier, Judith and Glenn Ellison (1997), Risk Taking by Mutual Funds as a Response to Incentives, Journal of Political Economy, 105:6, 1167-1200.

Chevalier, Judith and Glenn Ellison (1999), Career Concerns and Mutual Fund Managers, Quarterly Journal of Economics, 114, 389-432.

Dasgupta, Amil and Andrea Prat (2006), Information Aggregation in Financial Markets with Career Concerns, Journal of Economic Theory, forthcoming.

Dass, Nishant, Massimo Massa and Rajdeep Patgiri (2008), Mutual Funds and Bubbles: The Surprising Role of Contractual Incentives, Review of Financial Studies, 21, 51-99.

Drachter, Kerstin, Alexander Kempf and Michael Wagner (2007), Decision Processes in German Mutual Fund Companies: Evidence from a Telephone Survey, International Journal of Managerial Finance, 3:1, 49-69.

Eichberger, Jürgen, Simon Grant and Stephen P. King (1999), On Relative Performance Contracts and Fund Manager's Incentives, European Economic Review, 43, 135-161.

Fama, Eugene F. (1980), Agency Problems and the Theory of the Firm, Journal of Political Economy, 88, 288-307.

Farnsworth, Heber and Jonathan Taylor (2006), Evidence on the Compensation of Portfolio Managers, Journal of Financial Research, 29:3, 305-324.

Gibbons, Robert and Kevin J. Murphy (1990), Relative Performance Evaluation for Chief Executive Officers, Industrial and Labor Relations Review, 43, 30-51.

Gibbons, Robert and Kevin J. Murphy (1992), Optimal Incentive Contracts in the Presence of Career Concerns: Theory and Evidence, Journal of Political Economy, 100:3, 468-505.

Graham, John R. (1999), Herding Among Investment Newsletters: Theory and Evidence, Journal of Finance, 54:1, 237-268.

Graham, John R. and Campbell R. Harvey (2001), The Theory and Practice of Corporate Finance: Evidence from the Field, Journal of Financial Economics, 60, 187-243.

Grinblatt, Mark and Sheridan Titman (1989), Adverse Risk Incentives and the Design of Performance-based Contracts, Management Science, 35:7, 807-822.

Grinblatt, Mark, Sheridan Titman and Russ Wermers (1995), Momentum Investment Strategies, Portfolio Performance and Herding: A Study of Mutual Fund Behavior, American Economic Review, 85:5, 1088-1105.

Gümbel, Alexander (2005), Herding in Delegated Portfolio Management: When Is Comparative Performance Information Desirable?, European Economic Review, 49:3, 599626. 
Holmström, Bengt (1999), Managerial Incentive Problems: A Dynamic Perspective, Review of Economic Studies, 66:1, 169-182.

Jenter, Dirk and Fadi Kanaan (2006), CEO Turnover and Relative Performance Evaluation, NBER Working Paper 12068.

Kapur, Sandeep and Allan Timmermann (2005), Relative Performance Evaluation Contracts and Asset Market Equilibrium, Economic Journal, 115:506, 1077-1102.

Kempf, Alexander, Stefan Ruenzi and Tanja Thiele (2007), Employment Risk, Compensation Incentives and Managerial Risk Taking, Journal of Financial Economics, forthcoming.

Kouwenberg, Roy and William T. Ziemba (2007), Incentives and Risk Taking in Hedge Funds, Journal of Banking and Finance, 31, 3291-3310.

Lakonishok, Josef, Andrei Shleifer and Robert W. Vishny (1992), The Impact of Institutional Trading on Stock Prices, Journal of Financial Economics, 32, 23-43.

Lazear, Edward P. (2000), The Power of Incentives, American Economic Review, 90:2, 410414.

Li, Xi (2002), Performance, Herding, and Career Concerns of Individual Financial Analysts, Working Paper, Vanderbilt University.

Massa, Massimo and Rajdeep Patgiri (2007), Incentives and Mutual Funds Performance: Higher Performance or just Higher Risk Taking?, Review of Financial Studies, forthcoming.

Massa, Massimo and Rajdeep Patgiri (2007a), Compensation and Managerial Herding: Evidence from the Mutual Fund Industry, Working Paper.

Menkhoff, Lukas, Ulrich Schmidt and Torsten Brozynski (2006), The Impact of Experience on Risk Taking, Overconfidence, and Herding of Fund Managers: Complementary Survey Evidence, European Economic Review, 50:7, 1753-1766.

Ottaviani, Marco and Peter Norman Sørensen (2006), The Strategy of Professional Forecasting, Journal of Financial Economics, 81:2, 441-466.

Otten, Roger and Dennis Bams (2002), European Mutual Fund Performance, European Financial Management, 8:1, 75-101.

Ou-Yang, Hui (2003), Optimal Contracts in a Continuous-Time Delegated Portfolio Management Problem, Review of Financial Studies, 16:1, 173-208.

Palomino, Frédéric and Andrea Prat (2003), Risk Taking and Optimal Contracts for Money Managers, Rand Journal of Economics, 34:1, 113-137.

Prendergast, Canice and Lars Stole (1996), Impetuous Youngsters and Jaded Old-Timers: Acquiring a Reputation for Learning, Journal of Political Economy, 104:6, 11051134.

Shiller, Robert J. and John Pound (1989), Survey Evidence on Diffusion of Interest and Information Among Investors, Journal of Economic Behavior and Organization, 12:1, 47-66.

Stracca, Livio (2006), Delegated Portfolio Management, A Survey of the Theoretical Literature, Journal of Economic Surveys, 20:5, 823-848.

Welch, Ivo (2000), Views of Financial Economists on the Equity Premium and on Professional Controversies, Journal of Business, 73:4, 501-537.

Zwiebel, Jeffrey (1995), Corporate Conservatism and Relative Compensation, Journal of Political Economy, 103:1, 1-25. 


\section{TABLE 1. Comparison of the data sample with industry's structure}

Structure of the asset management industry in relation to respective country sub sample (by assets under management)

UNITED STATES GERMANY SWITZERLAND

$\mathrm{H}_{0}$ : no difference ${ }^{1)} \quad-0.753(0.451) \quad-0.930(0.352) \quad-0.385(0.700)$

Correlation $^{2)}$ with company size (by assets under management)

UNITED STATES GERMANY SWITZERLAND

Number of answered question- $\quad 0.260 * *(0.040) \quad 0.627 * * *(0.000) \quad 0.905^{* * *}(0.000)$ naires per company

The market data is taken from on the 'Pensions \& Investments' money managers directory 2003 (www.pionline.com), the annual report 2003 of the BVI (www.bvi.de), and the 'TIF' report of the SWX Swiss Exchange in cooperation with the SFA Swiss Funds Association (www.swx.com), respectively.

1) The table gives the $\mathrm{z}$-value of the Mann-Whitney U-Test with the p-value in parentheses.

2) The table gives the coefficient of the Pearson correlation with the p-value in parentheses.

3) Proxied by number of mutual funds offered.

Stars refer to level of significance: $* 10 \%, * * 5 \%, * * * 1 \%$. 
TABLE 2. Fund managers' personal characteristics ${ }^{1)}$

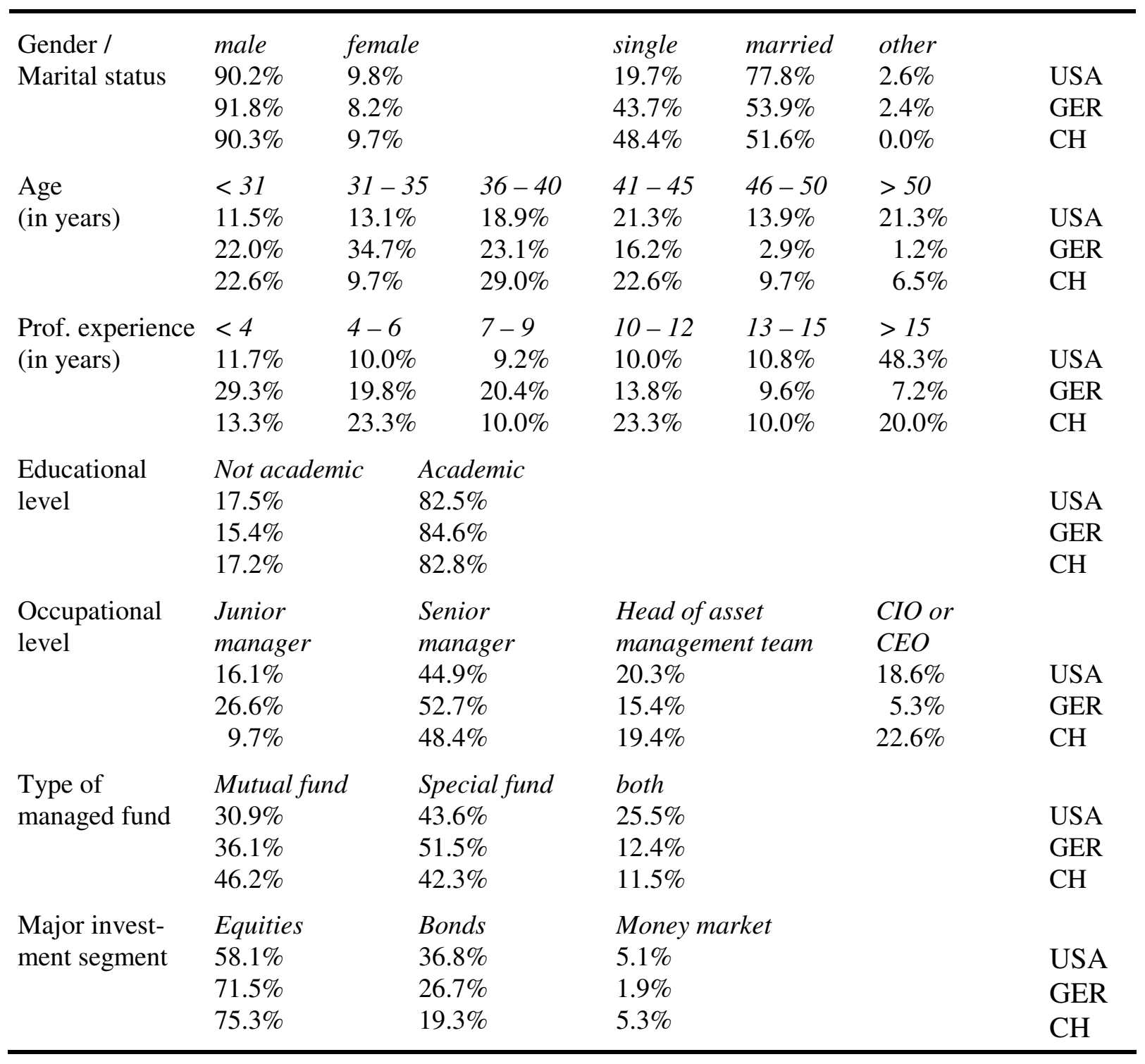

1) Regarding each item, the first row displays response from the United States $(n=122)$, the second row displays response from Germany $(n=173)$ and the third row displays response from Switzerland $(n=31)$. 
TABLE 3. Average bonus clustered by country and position

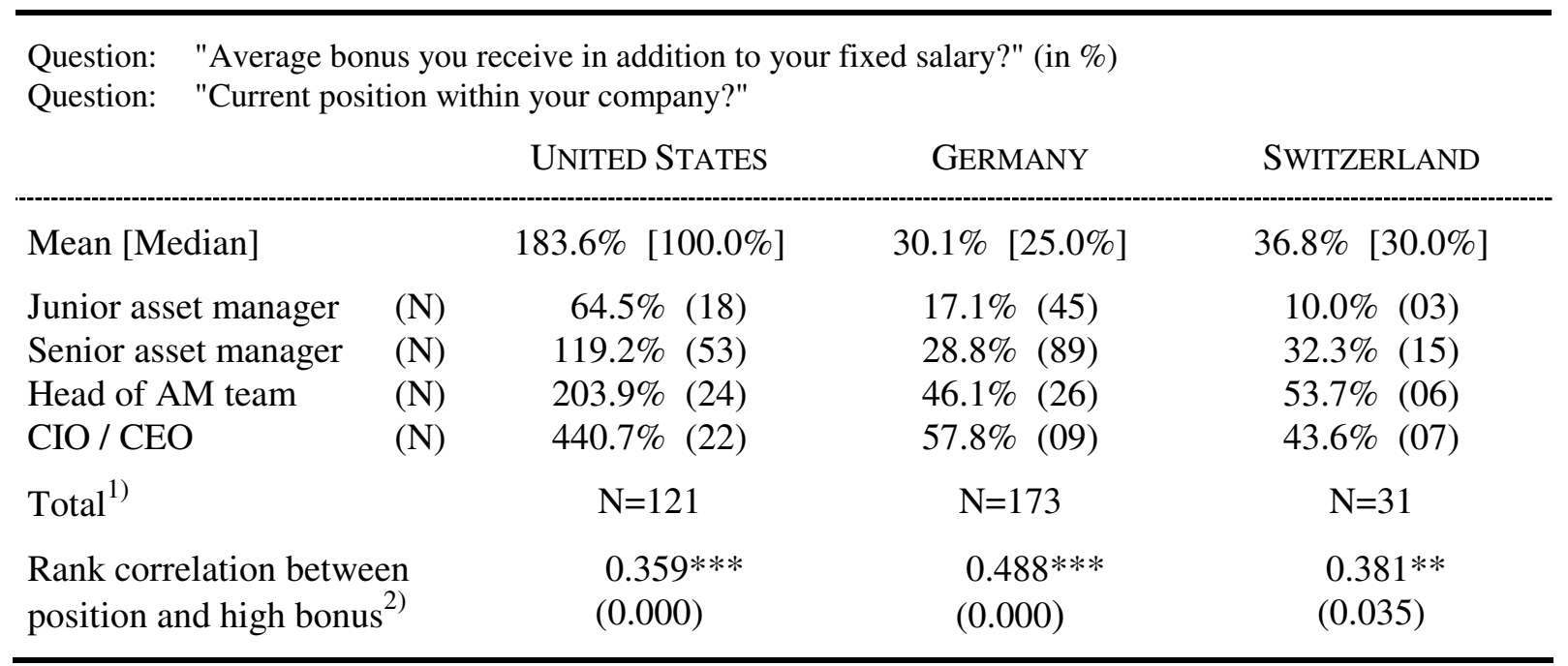

1) Total number of responses exceeds the cumulated number of responses by position, as a few managers did not disclose their current position.

2) The table gives the coefficient of the Spearman rank correlation with the p-value in parentheses.

Asterisks refer to level of significance: * $10 \%, * * 5 \%, * * * 1 \%$.

TABLE 4. Differences in bonus size between countries

\begin{tabular}{lcc}
\hline \multicolumn{2}{c}{$\mathrm{H}_{0}:$ no difference between countries regarding distribution of average bonus ${ }^{1)}$} \\
& UNITED STATES & GERMANY \\
\hline GERMANY & $-9.832 * * *(0.000)$ & $-1.156(0.248)$ \\
SWITZERLAND & $-5.047 * * *(0.000)$ & -
\end{tabular}

1) The table gives the z-value of the Mann Whitney U-test with p-value in parentheses. Asterisks refer to level of significance: $* 10 \%, * * 5 \%, * * * 1 \%$. 
TABLE 5. Institutional determinants of bonus payment

\begin{tabular}{lccccc}
\hline & \multicolumn{3}{c}{ TOBIT regression of high bonus ${ }^{1)}$} \\
& UNITED STATES & CONTINENTAL EUROPE \\
\hline Constant & $-789.229 * * *$ & $(0.003)$ & $-25.454^{* *}$ & $(0.045)$ \\
Gender (being female) & 15.701 & $(0.788)$ & $6.827 *$ & $(0.050)$ \\
Marital status (being rather married) & 41.247 & $(0.401)$ & 1.952 & $(0.298)$ \\
Higher age & -38.851 & $(0.307)$ & -0.222 & $(0.928)$ \\
More experienced & 3.356 & $(0.918)$ & -2.129 & $(0.268)$ \\
More research and data procurement & 5.980 & $(0.101)$ & 0.088 & $(0.608)$ \\
Higher educational level & 4.134 & $(0.935)$ & -0.264 & $(0.922)$ \\
Higher position & $204.131^{* * *}(0.000)$ & $18.542^{* * * *}(0.000)$ \\
Managing rather special funds & 30.916 & $(0.194)$ & -0.966 & $(0.486)$ \\
Managing rather equities than bonds & 27.663 & $(0.519)$ & 3.565 & $(0.116)$ \\
Working for bigger companies & $54.433^{* *}$ & $(0.021)$ & $3.778^{* * *}(0.001)$ \\
Managing bigger fund volumes & 38.743 & $(0.103)$ & 0.699 & $(0.660)$ \\
Adjusted R ${ }^{2}$ & \multicolumn{3}{c}{0.298} & & 0.296 \\
Number & \multicolumn{2}{c}{75} & & 128 \\
\hline
\end{tabular}

1) The table gives the coefficients of the TOBIT regression with p-value in parentheses. Asterisks refer to level of significance: $* 10 \%, * * 5 \%, * * * 1 \%$.

TABLE 6. Criteria for the size of bonus

Question: "If you receive a performance-based remuneration, which criteria determine the size of that bonus?" Six answer categories ranging from "highest relevance" (coded as 1) to "no relevance" (coded as 6).

\begin{tabular}{|c|c|c|c|c|c|}
\hline & \multicolumn{2}{|c|}{$\begin{array}{l}\text { Share of highest } \\
\text { relevance }\end{array}$} & \multirow{2}{*}{$\begin{array}{c}\mathrm{H}_{0}: \text { no } \\
\text { difference }^{2)} \\
{[3]}\end{array}$} & \multicolumn{2}{|c|}{$\begin{array}{l}\text { Rank correlation } \\
\text { with high bonus }\end{array}$} \\
\hline & $\begin{array}{c}{[1]} \\
\text { UNITED } \\
\text { STATES }\end{array}$ & $\begin{array}{c}{[2]} \\
\text { CONTINENTAL } \\
\text { EUROPE }\end{array}$ & & $\begin{array}{c}{[4]} \\
\text { UNITED } \\
\text { STATES }\end{array}$ & $\begin{array}{c}{[5]} \\
\text { CONTINENTAL } \\
\text { EUROPE }\end{array}$ \\
\hline $\begin{array}{l}\text { Business develop- } \\
\text { ment of company }\end{array}$ & $23.2 \%$ & $29.5 \%$ & $\begin{array}{l}-1.890^{*} \\
(0.059)\end{array}$ & $\begin{array}{l}0.247 * * * \\
(0.008)\end{array}$ & $\begin{array}{c}0.054 \\
(0.464)\end{array}$ \\
\hline $\begin{array}{l}\text { Relative fund } \\
\text { performance }\end{array}$ & $44.2 \%$ & $27.9 \%$ & $\begin{array}{l}-2.339 * * \\
(0.019)\end{array}$ & $\begin{array}{c}0.153 \\
(0.103)\end{array}$ & $\begin{array}{l}0.376^{* * *} \\
(0.000)\end{array}$ \\
\hline $\begin{array}{l}\text { Subjective assessment } \\
\text { by superiors }\end{array}$ & $24.5 \%$ & $17.8 \%$ & $\begin{array}{l}-0.859 \\
(0.390)\end{array}$ & $\begin{array}{c}0.121 \\
(0.196)\end{array}$ & $\begin{array}{l}-0.145^{* *} \\
(0.048)\end{array}$ \\
\hline $\begin{array}{l}\text { Absolute fund } \\
\text { performance }\end{array}$ & $6.1 \%$ & $6.1 \%$ & $\begin{array}{l}-1.374 \\
(0.169)\end{array}$ & $\begin{array}{c}0.070 \\
(0.472)\end{array}$ & $\begin{array}{l}0.021 \\
(0.785)\end{array}$ \\
\hline
\end{tabular}

1) The share of highest relevance represents the answers given to category 1 .

2) The table gives the z-value of the Mann Whitney U-test with p-value in parentheses.

3) The table gives the coefficients of the Spearman rank correlation with the p-value in parentheses.

Asterisks refer to level of significance: $* 10 \%$, ** 5\%, *** $1 \%$. 


\section{TABLE 7. Determinants of high working effort}

\begin{tabular}{|c|c|c|}
\hline & UNITED STATES & CONTINENTAL EUROPE \\
\hline $\begin{array}{l}\text { Spearman rank correlation between high } \\
\text { bonus and high working effort }{ }^{1)}\end{array}$ & $0.419 * * *(0.000)$ & $0.309 * * *(0.000)$ \\
\hline \multicolumn{3}{|l|}{$\begin{array}{l}\text { Ordered PROBIT regression of } \\
\text { high working effort }{ }^{2)}\end{array}$} \\
\hline Higher bonus & $0.001 * \quad(0.056)$ & $0.010 * * *(0.005)$ \\
\hline Higher position & $(0.472)$ & $0.105 \quad(0.424)$ \\
\hline Higher age & $(0.200)$ & $(0.446)$ \\
\hline More experience & $0.015 \quad(0.875)$ & $(0.759)$ \\
\hline Working for bigger companies & $0.303 * * *(0.000)$ & $0.026 \quad(0.579)$ \\
\hline Pseudo $\mathrm{R}^{2}$ & 0.100 & 0.036 \\
\hline Number & 112 & 189 \\
\hline
\end{tabular}

Ordered PROBIT regression with

additional variables ${ }^{3)}$

Higher educational level $\quad-0.408 * * *(0.010)$

More research and data procurement $\quad 0.025^{* *} \quad(0.017)$

Managing bigger funds

$0.209 * * *(0.002)$

Pseudo R ${ }^{2}$

0.132

Number

93

0.051

182

1) The table gives the coefficients of the Spearman rank correlation with p-value in parentheses.

2) The table gives the coefficients of the ordered PROBIT regression with p-value in parentheses.

3) In addition to the core variables mentioned above, we added additional variables to improve the explanatory power of the regression. By doing so, the variable "bonus" loses its significant influence in the United States.

Asterisks refer to level of significance: $* 10 \%, * * 5 \%, * * * 1 \%$. 
TABLE 8. Determinants of degree of active management

\begin{tabular}{|c|c|c|c|c|}
\hline \multirow[b]{2}{*}{$\begin{array}{l}\text { Spearman rank correlation between high } \\
\text { bonus and active management }{ }^{1)}\end{array}$} & \multicolumn{2}{|c|}{ UNITED STATES } & \multicolumn{2}{|c|}{ CONTINENTAL EUROPE } \\
\hline & -0.058 & $(0.525)$ & -0.015 & $(0.840)$ \\
\hline \multicolumn{5}{|l|}{$\begin{array}{l}\text { Ordered PROBIT regression of } \\
\text { degree of active management }{ }^{2)}\end{array}$} \\
\hline Higher bonus & -0.000 & $(0.967)$ & 0.001 & $(0.846)$ \\
\hline Higher position & 0.062 & $(0.734)$ & 0.073 & $(0.608)$ \\
\hline Higher age & 0.006 & $(0.961)$ & -0.165 & $(0.123)$ \\
\hline More experience & -0.081 & $(0.484)$ & $0.139 *$ & $(0.091)$ \\
\hline Working for bigger companies & 0.017 & $(0.833)$ & 0.063 & $(0.208)$ \\
\hline Pseudo $\mathrm{R}^{2}$ & \multicolumn{2}{|c|}{0.006} & \multicolumn{2}{|c|}{0.016} \\
\hline Number & \multicolumn{2}{|c|}{112} & \multicolumn{2}{|c|}{182} \\
\hline
\end{tabular}

Ordered PROBIT regression with additional variables ${ }^{3)}$

More research and data procurement

Managing rather mutual funds than spe- $\quad 0.234 * * \quad(0.020)$

cial funds
Pseudo $\mathrm{R}^{2}$
0.077
0.067
Number
101

1) The table gives the coefficients of the Spearman rank correlation with p-value in parentheses.

2) The table gives the coefficients of the ordered PROBIT regression with p-value in parentheses.

3) In addition to the core variables mentioned above, we added additional variables to improve the explanatory power of the regression. By doing so, the variable "age" gains significance at 5\% level in Continental Europe and the variable "experience" gains significance at $1 \%$ level in Continental Europe. Both without any changes in the sign of the variables. 
TABLE 9. Determinants of fundamental orientation

\begin{tabular}{|c|c|c|}
\hline & UNITED STATES & CONTINENTAL EUROPE \\
\hline $\begin{array}{l}\text { Spearman rank correlation between high } \\
\text { bonus and fundamental orientation }{ }^{1)}\end{array}$ & $(0.065)$ & $0.215^{* * *}(0.002)$ \\
\hline \multicolumn{3}{|l|}{$\begin{array}{l}\text { Ordered PROBIT regression of } \\
\text { fundamental orientation }{ }^{2}\end{array}$} \\
\hline Higher bonus & $0.001 * * \quad(0.013)$ & $(0.079)$ \\
\hline Higher position & $-0.715 * * *(0.000)$ & $-0.028 \quad(0.845)$ \\
\hline Higher age & $-0.044 \quad(0.703)$ & $(0.930)$ \\
\hline More experience & $(0.192)$ & $-0.025 \quad(0.764)$ \\
\hline Working for bigger companies & $-0.004 \quad(0.963)$ & $0.158 * * *(0.002)$ \\
\hline Pseudo $\mathrm{R}^{2}$ & 0.112 & 0.046 \\
\hline Number & 113 & 190 \\
\hline
\end{tabular}

Ordered PROBIT regression with additional variables ${ }^{4}$

More research and data procurement Managing rather equities than bonds

Pseudo R ${ }^{2}$

Number

$\begin{array}{cc}0.031 * * *(0.008) & 0.024 * *(0.014) \\ & 0.087 * *(0.049) \\ 0.160 & 0.078 \\ 96 & 146\end{array}$

1) The table gives the coefficients of the Spearman rank correlation with p-value in parentheses.

2) The table gives the coefficients of the ordered PROBIT regression with p-value in parentheses.

3) In addition to the core variables mentioned above, we added additional variables to improve the explanatory power of the regression. By doing so, the variables "bonus" and "company size" lose their significant influence in Continental Europe.

Asterisks refer to level of significance: $* 10 \%, * * 5 \%, * * * 1 \%$. 
TABLE 10. Coefficients of bonus size and relative performance based bonus

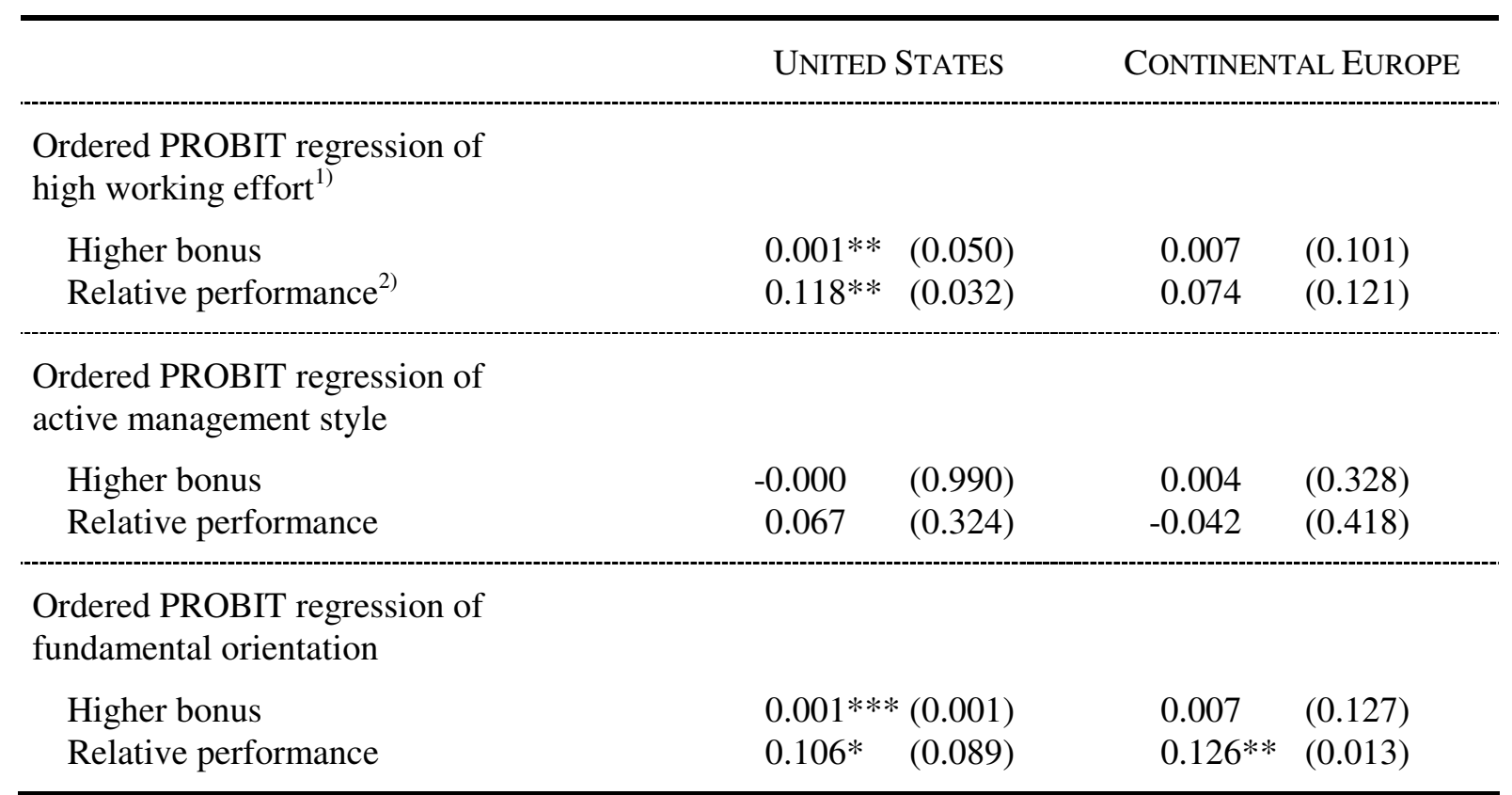

1) The table gives the coefficients of the ordered PROBIT regression with p-value in parentheses. Exogenous variables - not shown here - are the same as documented in Tables 7 to 9. They include position and company size (to cover determinants of bonus) and age and experience (to cover further career incentives).

2) This variable is measured as absolute minus relative fund performance (see Table 6). Larger positive values indicate a more important role of relative versus absolute fund performance, according to variable coding.

Asterisks refer to level of significance: * $10 \%, * * 5 \%, * * * 1 \%$. 


\section{APPENDIX 1. Questionnaire}

Gender: $\quad$ Male $\quad$ Female

Marital status: $\quad$ Single $\quad$ Married Other

How old are you?

\begin{tabular}{|l|l|l|l|l|l|}
\hline$<31$ & $31-35$ & $36-40$ & $41-45$ & $46-50$ & $>50$ \\
\hline
\end{tabular}

Professional experience in asset management (in years):

\begin{tabular}{|l|l|l|l|l|l|}
\hline$<4$ & $4-6$ & $7-9$ & $10-12$ & $13-15$ & $>15$ \\
\hline
\end{tabular}

Average working hours per week:

\begin{tabular}{|l|l|l|l|l|l|}
\hline$<41$ & $41-45$ & $46-50$ & $51-55$ & $56-60$ & $>60$ \\
\hline
\end{tabular}

Average number of hours per week for data procurement and research:

Educational level:

Non academic

Hours per week

Current position within your company: Junior Asset Manager

Academic

(Occupational level)

Head of AM team

Senior Asset Manager

$\mathrm{CIO} / \mathrm{CEO}$

Average bonus you receive in addition to your fixed salary:

- $\%$

Type of managed fund:

Mutual fund

Restricted / special / pension / hedge fund

Major investment segment:

Equities

Bonds

Money market

Your company's total assets under management (in billion of \$):

\begin{tabular}{|l|l|l|l|l|l|}
\hline$<5$ & $5-10$ & $10-20$ & $20-50$ & $50-100$ & $>100$ \\
\hline
\end{tabular}

Your personal responsibility for assets under management (in million of \$):

\begin{tabular}{|l|l|l|l|l|l|}
\hline$<50$ & $50-250$ & $250-1,000$ & $1,000-2,500$ & $2,500-10,000$ & $>10,000$ \\
\hline
\end{tabular}

If you receive a performance-based remuneration, which criteria determine the size of that bonus?

Absolute fund performance

Relative fund performance

Business development of the investment company

Subjective assessment by superiors and colleagues

Please assess the following sources of information used in making investment decision:

Fundamental facts about the company / market

\section{Please describe your management style:}

How actively (i.e. high tracking error) can you manage your portfolio at most?

How actively (i.e. high tracking error) do you manage your portfolio in fact? 
APPENDiX 2.

FIGURE 1. Distribution of bonus payments

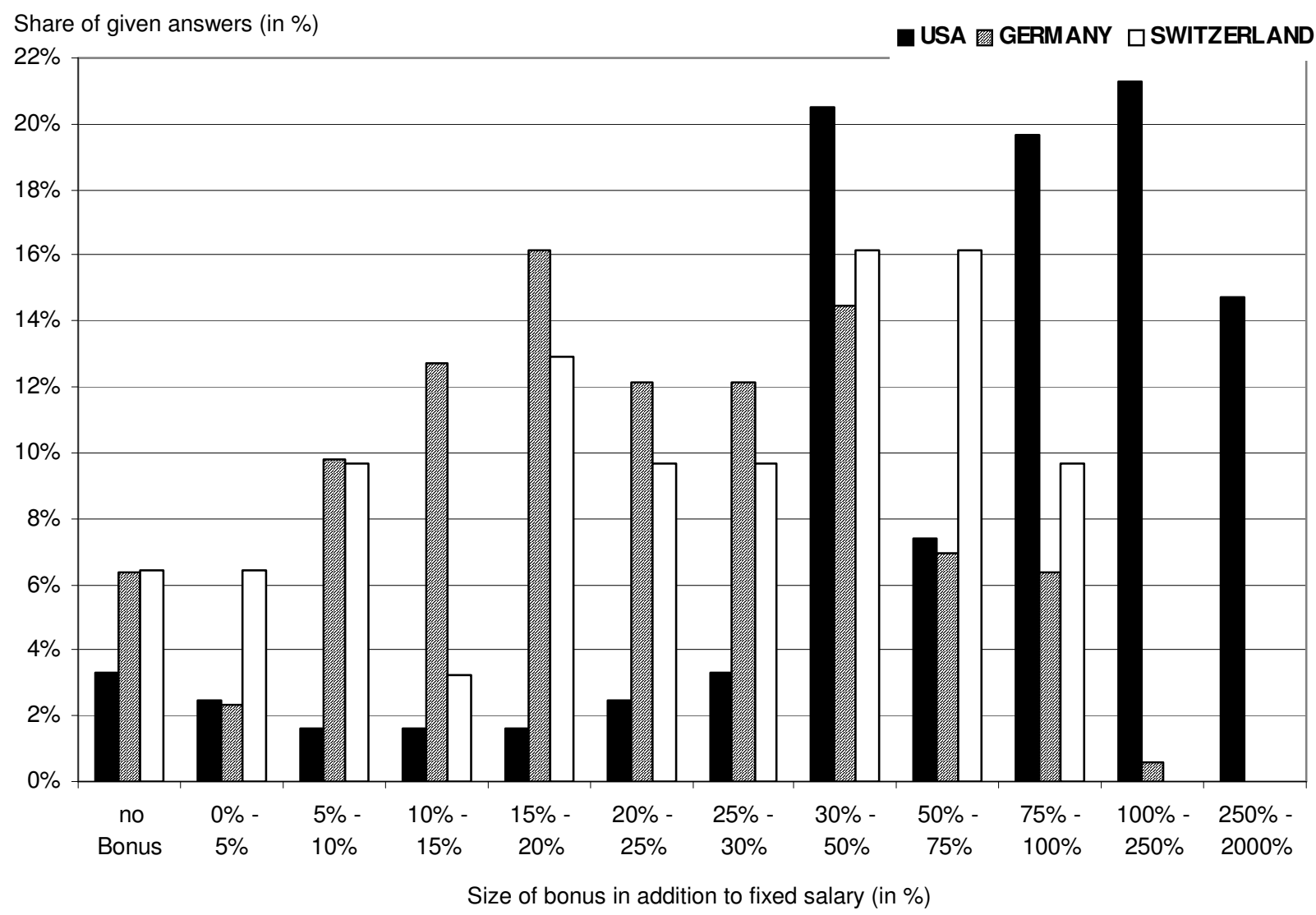

FIGURE 2. Working effort and relation to bonus

Question: "Average working hours per week."

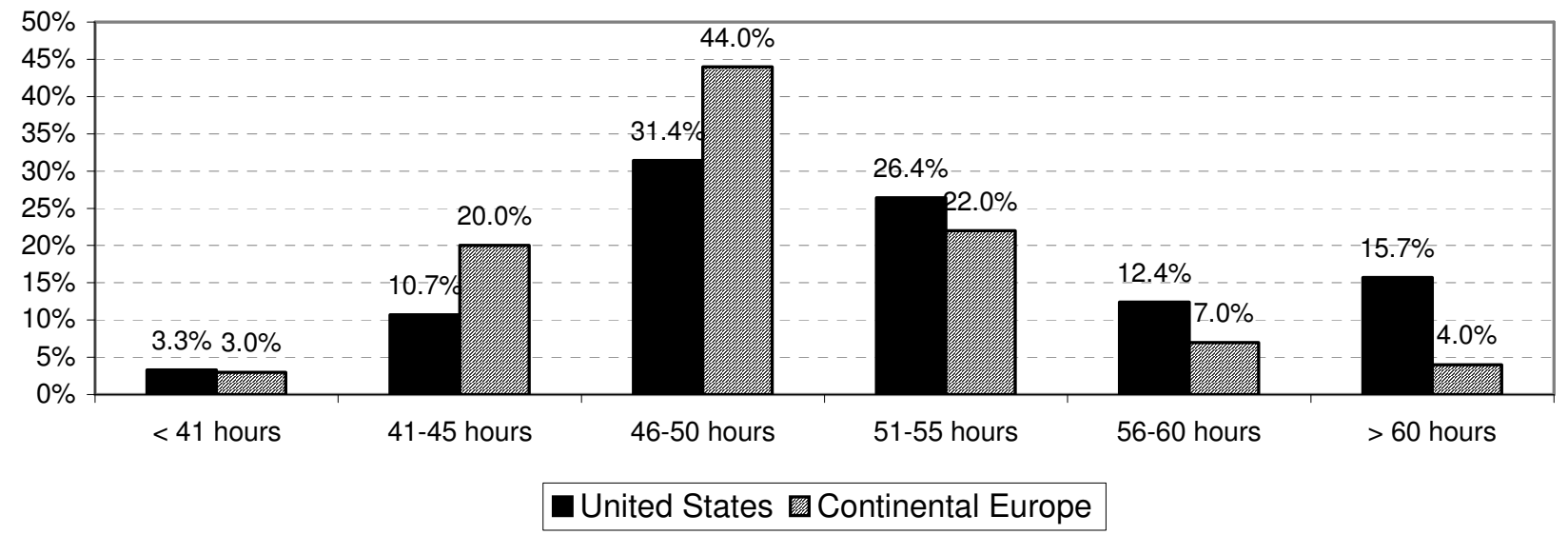

$\mathrm{H}_{0}$ : no difference between the United States and continental Europe, z-value of the Mann-Whitney U-Test: 4.089*** (0.000). The respective p-value is given in parentheses. Asterisks refer to level of significance: $* 10 \%, * * 5 \%, * * * 1 \%$. 


\section{FIGURE 3. Difference between tracking error allowed and practiced (i.e. the degree of active management)}

Question: $\quad$ "Please describe your trading style: I) "What trading style are your allowed?" II) "What trading style do you actually follow?" Six answer categories ranging from 1 "high tracking error" to 6 "indexing".

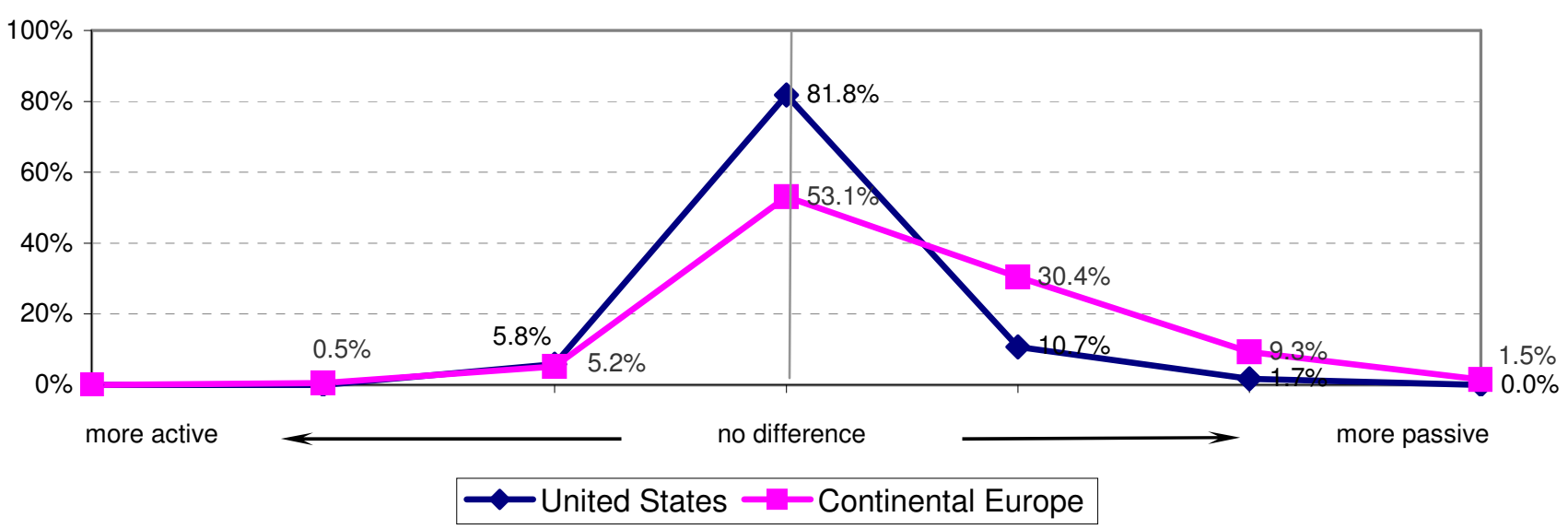

$\mathrm{H}_{0}$ : no difference between the United States and continental Europe, z-value of the Mann-Whitney U-Test: $4.900 * * *(0.000)$. The respective p-value is given in parentheses. Asterisks refer to level of significance: * $10 \%$, ** $5 \%, * * * 1 \%$.

\section{FIGURE 4. Fundamental orientation}

Request: "Please assess the following sources of information used in making investment decisions: Fundamental facts about the company / market [...]" Six answer categories ranging from "highest relevance" (coded as 1) to "no relevance" (coded as 6).

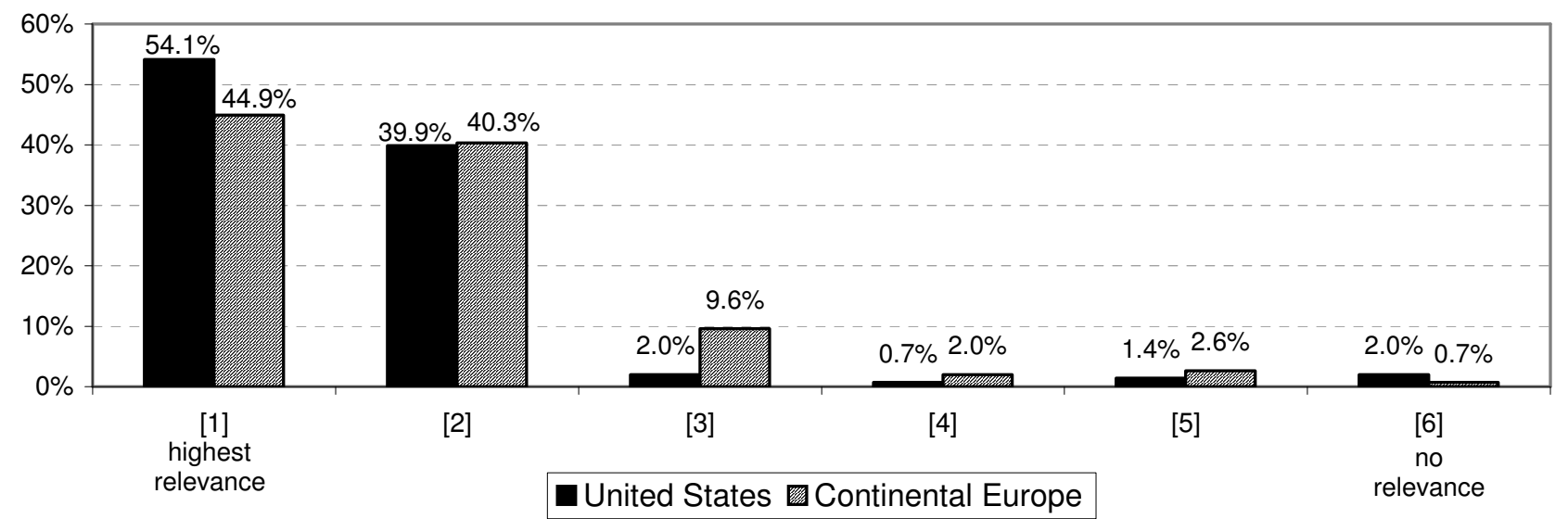

$\mathrm{H}_{0}$ : no difference between continental Europe and the United States, Z-value of the Mann-Whitney U-Test: $-2.331 * *(0.020)$. The respective $p$-value is given in parentheses. Asterisks refer to level of significance:

$* 10 \%$, ** $5 \%$, *** $1 \%$. 